\title{
Characteristics of COVID-19 Infection in Patients without a History of Travel to Infected Areas or Direct Contact with a Case-Patient
}

\begin{abstract}
BinBin Li
YongJia County People's Hospital, Zhejiang, China

Objective: Little is known about COVID-19 patients who have not traveled to infected areas or had direct contact with infected persons. This report describes the clinical features of 28 such patients with confirmed COVID-19 infection.

Methods: Data on clinical characteristics during hospitalization were collected.

Results: Epidemiological exposures were investigated among patients reporting no travel to infected areas or direct contact with a case-patient. Patients presented with various symptoms, increased levels of inflammatory markers, and consolidation or ground-glass opacification on computed tomography scans. Conclusions: The present report contributes critical information on the clinical presentation of COVID19 patients without typical epidemiological exposures. (J Nippon Med Sch 2020; 87: 240-242)
\end{abstract}

Key words: COVID-19, epidemiology, novel coronavirus, computed tomography, infection

\section{Introduction}

Cases of pneumonia of unknown cause have been reported since December 2019 in Wuhan City, Hubei Province. On January 7, 2020, the cause was classified as novel coronavirus (NCP), which the World Health Organization refers to as COVID-19 ${ }^{1}$. The epidemiological and clinical characteristics of COVID-19 cases have been reported ${ }^{2}$, but little is known about COVID-19 patients who have not traveled to infected areas or had direct contact with infected persons. This report describes the clinical features of 28 such patients with confirmed COVID-19 infection.

\section{Methods}

Clinical data were collected at a hospital in Zhejiang Province, China (YongJia County People's Hospital). The present patients were admitted to hospital from January 23, 2020 through February 11, 2020; 5 remain in quarantine at this writing. Epidemiological analysis showed that they had not traveled to an infected area or had direct contact with a known infected person. During hospitalization, oral swabs, anal swabs, and blood samples were collected and sent to the Center for Disease Control and
Prevention in China for identification of COVID-19 with a quantitative polymerase chain reaction assay. Chest computed tomography (CT) scans were obtained at approximately 3-day intervals. All patients had genetically confirmed COVID-19 infection and received standard care. This study was approved by the ethics committees of the hospitals, and the requirement for informed consent was waived.

\section{Results}

The present patients had no history of travel to an infected area or direct contact with a case-patient. The possible epidemiological exposures of these patients are shown in Table 1. Several patients had multiple potential epidemiological exposures. Half the patients lived in the same village as persons with COVID-19 but denied direct contact. More than 20\% of patients had recently traveled to an uninfected area. About $25 \%$ of patients had been to a shopping mall (for shopping or working) or attended a dinner party (mainly wedding ceremonies or family reunions). Four patients had recently visited healthcare facilities for prescription of hypertension medication. No potential epidemiological exposures were identified for 2

Correspondence to BinBin Li, YongJia County People's Hospital, No.37 Yongzhong Road, Yongjia County, Wenzhou City, Zhejiang Province 325100, China

E-mail: xll123qwe@qq.com

https://doi.org/10.1272/jnms.JNMS.2020_87-411

Journal Website (https://www.nms.ac.jp/sh/jnms/) 
COVID-19 Infection without Epidemiological Exposure

Table 1 Possible epidemiological exposures of present patients

\begin{tabular}{lc}
\hline \multicolumn{1}{c}{ Epidemiological exposures } & No. of patients \\
\hline Established epidemiological exposure & \\
Travel to infected area & None \\
Direct contact with case-patient & None \\
Potential epidemiological exposure & \\
Travel to non-infected area & 6 \\
Visited shopping mall & 8 \\
Attended dinner party & 9 \\
Contact with healthcare facility & 4 \\
Living in same village as COVID-19 patient & 14 \\
Unknown & 2 \\
\hline
\end{tabular}

Table 2 Clinical characteristics of COVID-19 patients without epidemiological exposures

\begin{tabular}{|c|c|}
\hline \multicolumn{2}{|c|}{ Patients without epidemiological exposures $(n=28)$} \\
\hline \multicolumn{2}{|l|}{ Demographics } \\
\hline Age $^{a}$ & $56(24)$ \\
\hline Gender (Female) $)^{b}$ & $11(39.29)$ \\
\hline \multicolumn{2}{|l|}{ Medical history } \\
\hline $\mathrm{HTN}^{\mathrm{b}}$ & $4(14.29)$ \\
\hline \multicolumn{2}{|l|}{ Symptoms } \\
\hline Cough & $12(42.86)$ \\
\hline Feverb & $10(35.71)$ \\
\hline Diarrhea $^{b}$ & $2(7.14)$ \\
\hline Sore throat ${ }^{\mathrm{b}}$ & $9(32.14)$ \\
\hline Chest pain ${ }^{b}$ & $4(14.29)$ \\
\hline \multicolumn{2}{|l|}{$\mathrm{CT}$} \\
\hline Unilateral lung involvement $\mathrm{t}^{\mathrm{b}}$ & $7(25.00)$ \\
\hline Bilateral lung involvement ${ }^{b}$ & $21(75.00)$ \\
\hline \multicolumn{2}{|l|}{ Laboratory tests } \\
\hline \multicolumn{2}{|l|}{ Blood cell count $\left(10^{9} / \mathrm{L}\right)$} \\
\hline White blood cellsc & $7.24(3.45)$ \\
\hline Neutrophilsc & $1.42(0.50)$ \\
\hline Lymphocytes ${ }^{c}$ & $1.61(0.45)$ \\
\hline Plateletsc & $223.31(57.48)$ \\
\hline Eosinophilic granulocytes ${ }^{a}$ & $0.09(0.10)$ \\
\hline \multicolumn{2}{|l|}{ Inflammatory markers } \\
\hline hs-CRPa (mg/L) & $10.63(13.73)$ \\
\hline $\mathrm{PCT}^{\mathrm{a}}(\mathrm{ng} / \mathrm{mL})$ & $0.05(0.04)$ \\
\hline $\mathrm{ESR}^{\mathrm{a}}(\mathrm{mm} / \mathrm{h})$ & $13.45(15.06)$ \\
\hline \multicolumn{2}{|l|}{ Cardiac enzyme } \\
\hline $\mathrm{CKMB}^{\mathrm{c}}(\mathrm{mmol} / \mathrm{L})$ & $53.89(31.65)$ \\
\hline \multicolumn{2}{|l|}{ Medications } \\
\hline Interferonc $^{c}$ & $28(100.00)$ \\
\hline Lopinavirc & $28(100.00)$ \\
\hline Arbidolc & $12(42.86)$ \\
\hline
\end{tabular}

a: Median (IQR); b: n (\%); c: Mean \pm SD

Abbreviations: HTN, hypertension; CT, computed tomography; hs-CRP, high-sensitivity C-reactive protein; PCT, procalcitonin; ESR, erythrocyte sedimentation rate; $\mathrm{CKMB}$, creatine kinase-MB Isoenzyme; IQR, interquartile range; SD, standard deviation. patients, despite our best efforts.

The median age of the present patients was 56 years (interquartile range, 48-72 years), and 11 (39.29\%) were female. Twelve patients presented with cough only; the remaining patients had additional symptoms, including fever $(35.71 \%, \mathrm{n}=10)$, diarrhea $(7.14 \%, \mathrm{n}=2)$, sore throat $(32.14 \%, n=9)$, and chest pain $(14.29 \%, n=4)$. No patient required respiratory support with noninvasive ventilation or extracorporeal membrane oxygenation (ECMO) ${ }^{3}$. Laboratory tests of blood cell count, inflammatory markers, and cardiac enzymes were reported: hs-C-reactive protein and lymphocyte count were elevated (Table 2). All patients had consolidation or ground-glass opacification (7 had unilateral lung involvement; 21 had bilateral lung involvement). As of February 27, 2020, all patients had recovered, and 5 remained in hospital quarantine. Empirical therapy, including interferon, lopinavir, and arbidol, was used to treat COVID-19.

\section{Discussion}

Although the source of COVID-19 has not yet been determined, the similarity at the whole-genome level between its viral sequence and that of the coronavirus Rhinolophus chinensis in China was reported to be $96 \%{ }^{4}$. However, the characteristics of the current world COVID-19 outbreak differ from those in the early stage $e^{5,6}$. More patients without a history of travel to an infected area or direct contact with a case-patient were diagnosed as having COVID-19, indicating that possibility of COVID-19 candidates without established epidemiological exposures must be considered.

Similar patterns of possible epidemiological exposures were found in this analysis. Several patients lived in the same village as known COVID-19 patients but denied contact. A full-scale review showed no conclusive evidence of direct or accidental contact in public areas, al- 
though 9 patients lived within 6 blocks of COVID-19 patients. This suggests that home quarantine is necessary. COVID-19 was diagnosed in a few patients after they had traveled to areas without known infections, indicating a potential larger epidemic area and underestimation of the rate of viral spread. Shopping malls and catering businesses pose a high risk of infection, given the outbreak of COVID-19 during spring festival. The source of infection could not be determined for 4 patients with hypertension who sought drug prescriptions at different healthcare facilities. However, special care should be taken to limit visits to hospitals in such conditions.

This study provides information on the clinical characteristics of patients without typical epidemiological exposures. Close monitoring and repeated multiple-sample testing may be required in hospitals specialized in quarantining and treating patients with COVID-19. Epidemiological investigation and presence of fever were insufficient to screen for potential COVID-19 candidates.

Most of the present patients were older than 50 years but few had comorbidities; only 4 had a medical history of hypertension. This suggests that this age group has greater susceptibility to COVID-19, regardless of comorbidity status. The patients were predominantly male, as was the case in a previous study ${ }^{7}$. Disparity in symptoms suggests that screening tests may need to be expanded in hospitals. Twelve patients presented with cough only, and 7 had mild cough. However, consolidation or ground-glass opacification was found in all patients, suggesting that more-aggressive treatment strategies are necessary for early pneumonia. Additionally, CT scanning may serve as a valid screening tool for identification of COVID-19. Full recovery was expected in all patients, which indicates that COVID-19 is mild in patients without epidemiological exposures. The main limitation of this study is the investigation of contact with a casepatient, which is difficult to completely exclude. These data contribute critical information on the clinical presentation of COVID-19 in patients without known epidemiological exposures.

Conflict of Interest: The author has no conflict of interest.

\section{References}

1. Jernigan DB, Team CC-R. Update: Public Health Response to the Coronavirus Disease 2019 Outbreak: United States, February 24, 2020. MMWR Morb Mortal Wkly Rep. 2020;69(8):216-9.

2. Velavan TP, Meyer CG. The COVID-19 epidemic. Trop Med Int Health. 2020;25(3):278-80.

3. Susak S, Redzek A, Rosic M, Velicki L, Okiljevic B. Development of cardiopulmonary bypass: A historical review. Srp Arh Celok Lek. 2016;144(11-12):670-5.

4. Zhou P, Yang XL, Wang XG, et al. A pneumonia outbreak associated with a new coronavirus of probable bat origin. 2020;579(7798):270-3.

5. Haider N, Yavlinsky A, Simons D, et al. Passengers' destinations from China: low risk of Novel Coronavirus (2019$\mathrm{nCoV})$ transmission into Africa and South America. Epidemiol Infect. 2020;148:e41.

6. Yoon SH, Lee KH, Kim JY, et al. Chest Radiographic and CT Findings of the 2019 Novel Coronavirus Disease (COVID-19): Analysis of Nine Patients Treated in Korea. Korean J Radiol. 2020.

7. Li Q, Guan X, Wu P, et al. Early Transmission Dynamics in Wuhan, China, of Novel Coronavirus-Infected Pneumonia. N Engl J Med. 2020.

(Received, March 2, 2020)

(Accepted, April 2, 2020)

Journal of Nippon Medical School has adopted the Creative Commons Attribution-NonCommercial-NoDerivatives 4.0 International License (https://creativecommons.org/licenses/by-nc-nd/4.0/) for this article. The Medical Association of Nippon Medical School remains the copyright holder of all articles. Anyone may download, reuse, copy, reprint, or distribute articles for non-profit purposes under this license, on condition that the authors of the articles are properly credited. 